\title{
Sperm Lipid Peroxidation and Antioxidants Activities as Predictors of Pregnancy Outcomes after Density Gradient Centrifugation in Medical Assistance Procreation
}

\author{
Hasnae Debbarh ${ }^{1^{*}}$, Smahane Aboulmaouahib ${ }^{2}$, Malak Jamil ${ }^{1}$, Khadija Mounaji ${ }^{1}$, \\ Omar Sefrioui ${ }^{2}$, Noureddine Louanjli ${ }^{2,3}$ and Rachida Cadi ${ }^{1}$ \\ ${ }^{1}$ Laboratory of Molecular Genetic Physiopathology and Biotechnology, Department of Biology, \\ Ain Chock Faculty of Sciences, HASSAN II University, Casablanca, Morocco. \\ ${ }^{2}$ Anfa Fertility Center, Private Clinic of in vitro Fertilization and Endoscopic Surgery, \\ Casablanca, Morocco. \\ ${ }^{3}$ Labomac IVF Center and Clinical Laboratory Medicine, Casablanca, Morocco.
}

Authors' contributions

This work was carried out in collaboration among all authors. All authors contributed to the conception and design of the study. Authors HD, SA, MJ and KM were responsible for acquisition of data.

Authors HD, SA and RC analyzed the data. All authors were involved in data interpretation. Author $H D$ drafted the manuscript, which was edited by authors NL, OS and RC. All authors read and approved the final manuscript.

Article Information

DOI: 10.9734/ARRB/2020/v35i1230322 Editor(s):

(1) Dr. Md. Torequl Islam, Federal University of Piaui, Brazil. Reviewers:

(1) Jeyasakthy Saniasiaya, University of Malaya, Malaysia. (2) Samuel Acquah, University of Cape Coast, Ghana. Complete Peer review History: http://www.sdiarticle4.com/review-history/64352

Original Research Article

Received 25 October 2020

Accepted 30 December 2020

Published 31 December 2020

\begin{abstract}
Aims: The purpose of this study was to assess the Density Gradient Centrifugation (DGC) effectiveness in spermatozoa selection by analyzing the oxidative stress profile and in pregnancy prediction outcomes of In Vitro Fertilization (IVF).

Study Design: This was a prospective study.

Place and Duration of Study: Department of Biology, laboratory of Physiopathology Molecular Genetic and Biotechnology. Ain Chock Faculty of Sciences, Hassan II University, Casablanca. And Anfa Fertility Center Private Clinic of in vitro fertilization and Endoscopic Surgery, Casablanca.
\end{abstract}

*Corresponding author: E-mail: debbarhhasnae@gmail.com; 
Methodology: We included 101 men patients subdivided into three groups. Group A with normal sperm parameters and a positive pregnancy; Group B with normal sperm parameters and a negative pregnancy; Group $\mathrm{C}$ with abnormal sperm parameters and a negative pregnancy. After DGC, lipid peroxidation (MDA) level, as well as the antioxidant enzyme activities of superoxide dismutase (SOD), glutathione reductase (GR) and catalase (CAT), were evaluated.

Results: Patients with normal and abnormal sperm parameters showed that MDA level, and antioxidant enzymes activities increased significantly from the pellet, to $80 \%$, and from $80 \%$ to $40 \%$ fractions. In addition, lipid peroxidation and enzymes activities levels were significantly lower in patients with positive pregnancy than in patients with negative pregnancy and especially those with abnormal spermatic parameters.

Conclusion: The DGC would select sperm not only motile and viable but with less oxidative stress. Moreover, the rate of lipid peroxidation and antioxidant enzyme activities could differentiate between patients with normal and abnormal spermatic parameters and between patients with positive and negative pregnancy outcome.

Keywords: DGC; semen; lipid peroxidation; antioxidant enzymes; pregnancy.

\section{INTRODUCTION}

Infertility is defined by the World health Organization (WHO) as the inability of a sexually active, non-contracepting couple to achieve pregnancy in one year [1].15\% of couples in the world suffer from infertility [2], of which $20 \%$ infertility is strictly male and $40 \%$ is mixed [3]. Nowadays, medically assisted procreation (MAP) is an ideal therapeutic solution that resolves some infertility issues by the use of several methods, namely in vitro fertilization (IVF), intrauterine insemination (IUI) and intracytoplasmic sperm injection (ICSI) [4].

The exploration of male infertility always begins with a clinical examination and a conventional sperm analysis. The latter is based on a microscopic evaluation that determines sperm quality via its count as well as sperm motility and morphology.

Although these parameters are one of the key examinations in the diagnosis of infertility, some sperms may require further analysis, especially when conventional parameters are normal $[5,6]$. Indeed, 6 to $27 \%$ of infertile men have normal sperm tests, normal physical examination, normal endocrine pattern, and no identifiable female cause, this is called idiopathic infertility [7].

Among the causes of male infertility, oxidative stress (OS) has been considered as one factor that impacts fertility status and thus, has been subjected to a lot of recent studies $[8,9]$. OS is a consequence of an imbalance between the production of reactive oxygen species (ROS) and antioxidant defense mechanisms in the body
$[10,11]$. Significant evidence indicates that a small amount of ROS is needed by spermatozoa to acquire fertilization capacity $[12,13]$. Several studies demonstrate that a low level of ROS is essential for hyperactivation, motility, acrosome reaction, and capacitation $[14,15,16,17]$. Nevertheless, increased ROS production levels by sperm or leukocytes can cause lipid peroxidation of sperm cell membrane, sperm DNA integrity impairment $[18,19,20]$ and sperm immobilization [21].

ROS is an important factor in the etiology of fragmentation, poor sperm quality especially DNA damage, decondensation, and apoptosis. Various studies have demonstrated that infertile men have higher ROS levels than fertile men $[22,23,24]$. Furthermore, DNA damage in spermatozoa has been associated with high levels of ROS [25]. Moreover, seminal reactive oxygen species have been considered as predictors of fertilization, embryo quality, and pregnancy rates after conventional in vitro fertilization and intracytoplasmic sperm injection $[26,27,28]$.

In MAP, density gradient centrifugation (DGC) is one of the methods used to improve sperm quality for artificial insemination or in vitro fertilization [29]. The goal of this technique is to select morphologically normal motile sperm, eliminate seminal plasma, cell debris, blood cells (such as leukocytes) as well as dead spermatozoa [30] that have significant ROS sources [31], causing a decrease in sperm function including mobility [32]. However, could the DGC go beyond conventional sperm selection, and give us an idea of the profile of oxidative stress in infertile patients particularly in those with idiopathic infertility? 
The purpose of this study was first to assess the DGC effectiveness in spermatozoa selection by analysis of the oxidative stress profile, and secondly to evaluate the oxidative stress profile after DGC as a predictor of pregnancy outcomes.

\section{MATERIALS AND METHODS}

\subsection{Patients' Selection}

This was a prospective study, approved by Anfa Fertility Center and physiopathology molecular genetics and biotechnology laboratory of Hassan II University, Casablanca (Morocco) informing the selected patients with consent. This study included 101 male patients with normal and abnormal sperm parameters whose ages were between 31 and 63 years. All patients underwent an analysis of sperm parameters which included mobility, morphology, counting according to WHO standards [1]. This analysis allowed us to distinguish three groups: Group A included 25 patients with normal sperm parameters and with a positive pregnancy, Group B contained 36 patients with normal sperm parameters and negative pregnancy and Group C included 40 patients with abnormal sperm parameters and negative pregnancy (Table 1). A pregnancy test was performed two weeks after the embryo transfer and pregnancy was positive when fetal heart activity was detected on transvaginal ultrasound four weeks after embryo transfer.

\subsection{Semen Collection and Preparation}

Semen samples were collected by masturbation after 3-5 days of sexual abstinence. Semen samples were firstly evaluated for spermogram analysis using a Makler chamber (Sefi Medical Instruments, Haifa, Israel) where it was analyzed for concentration, and motility and smears of the fresh semen were stained using the Diff- Quik kit (Baxter Healthcare Corporation, Inc., Mc Gaw Park, IL, USA) for assessment of sperm morphology. The smears were stained, rinsed in distilled water, air-dried and scored using Kruger's strict criteria [33].
Liquefaction was allowed to occur over at least 30 min before the spermatozoa were fractionated on a discontinuous two-step Pursperm gradient $(80 \% / 40 \%)$ as described by Aboulmaouahib et al. (2016) [34]. Then, the pellet, $80 \%$ and $40 \%$ fractions were lysed with lysis buffer $\mathrm{pH}=7.5(10$ mM EDTA, 1\% Glycerol, $1 \mathrm{mM}$ PMSF, $50 \mathrm{mM}$ Tris $\mathrm{HCl}, 10 \mathrm{mM}$ Mercaptoethanol) followed by sonication (80W 60s). After centrifugation at $12000 \mathrm{~g}$ for $15 \mathrm{~min}$ at $4^{\circ} \mathrm{C}$, the supernatants protein content was measured according to Bradford (1976) using bovine serum albumin (BSA) as standard [35].

\subsection{Enzymatic Antioxidant Activity Analysis and Lipid Peroxidation Evaluation}

Lipid peroxidation was estimated by thiobarbituric acid reactive substances (TBARS) reaction with malondialdehyde (MDA) as described by Samokyszyn and Marnett (1990) [36]. Briefly, $100 \mu \mathrm{l}$ of supernatant was added to $10 \%$ trichloroacetic (TCA) and $0.67 \%$ TBA. The tubes were placed in boiling water for 30 minutes and then cooled in ice to stop the reaction. Then a centrifugation at $8000 \mathrm{~g}$ for $10 \mathrm{~min}$ was performed. The MDA level was expressed as $\mathrm{mmol} / \mathrm{min} / \mu \mathrm{g}$ protein.

The SOD activity was measured according to Paoletti et al. (1986) [37]. The reaction medium contained: $5 \mathrm{mM}$ EDTA, $2.5 \mathrm{mM} \mathrm{MnCl}, 0.27 \mathrm{mM}$ $\mathrm{NADH}, \quad 3.9 \mathrm{mM}$ 2-mercaptoethanol, $50 \mathrm{mM}$ phosphate buffer $\mathrm{pH}=7$ and $50 \mu \mathrm{l}$ of the lysate. The enzyme activity was expressed as millimoles of $\mathrm{NADH}$ consumed $/ \mathrm{min} / \mu \mathrm{g}$ of protein.

To estimate the GR activity, the method of DI Llio et al. (1983) was used [38]. The reaction medium was composed of $1 \mathrm{mM}$ EDTA, $25 \mu \mathrm{M}$ GSSG, $1.5 \mu \mathrm{M} \mathrm{NADPH}, 50 \mu \mathrm{M}$ phosphate buffer $\mathrm{pH}=$ 7.4 and $50 \mu \mathrm{L}$ of lysate and the reading of the absorbance was carried out at $340 \mathrm{~nm}$ after the addition of $1.6 \mu \mathrm{M}$ of NADPH. The enzyme activity was expressed in millimoles of $\mathrm{NADPH}$ consumed/minute/ $\mathrm{\mu g}$ of protein.

Table 1. Characteristics of the studied population results are expressed as mean or percentage \pm standard deviation (SD)

\begin{tabular}{llll}
\hline & $\begin{array}{l}\text { Group A } \\
(\mathbf{n = 2 5 )}\end{array}$ & $\begin{array}{l}\text { Group B } \\
(\mathbf{n = 3 6 )}\end{array}$ & $\begin{array}{l}\text { Group C } \\
\mathbf{( n = 4 0 )}\end{array}$ \\
\hline Sperm parameters & Normal & Normal & Abnormal \\
Pregnancy & Positive & negative & negative \\
Numeration in $\mathrm{ml}$ & $60,1 \pm 27,7$ & $50,2 \pm 17,8$ & $31,7 \pm 18,2$ \\
Mobility \% & $50,5 \% \pm 0,31$ & $51,8 \% \pm 0,27$ & $31,4 \% \pm 0,23$ \\
Morphology \% & $45,5 \% \pm 0,20$ & $43,6 \% \pm 0,14$ & $25,7 \% \pm 0,33$ \\
\hline
\end{tabular}


The catalase activity was measured according to Aebi, (1984) [39]. The reaction medium was composed of $50 \mathrm{mM}$ phosphate buffer, $\mathrm{pH} 7$ and $30 \mu$ of lysate. The specific activity was given as millimoles of consumed $\mathrm{H} 2 \mathrm{O} 2 / \mathrm{min} / \mu \mathrm{g}$ of protein.

\subsection{Statistical Analysis}

The results are expressed as the mean or percentage of the total \pm standard deviation (SD) or SEM. Data was obtained with the Student's ttest for comparison of Malondialdehyde (MDA) levels and antioxidant enzymes activities in three fractions (Pellet, $80 \%$ and $40 \%$ ) and ANOVA test for comparison of lipid peroxidation level (MDA) and antioxidant enzymes activities (SOD, GR, CAT) in pellets sperm of group $A$, group $B$ and group C, using SPSS (Statistical Package for the Social Sciences) statistical significance was defined as $p<0.05$.

\section{RESULTS}

Our study was performed on semen from three groups: Group A included 40 patients with abnormal sperm parameters with negative pregnancy, Group B contained 36 patients with normal sperm parameters without pregnancy and Group C included 25 patients with normal sperm parameters and positive pregnancy. Sperm samples were centrifuged by density gradient (DGC) to select morphologically normal motile spermatozoa. Then, lipid peroxidation (MDA) levels, as well as superoxide dismutase (SOD), glutathione reductase (GR) and catalase (CAT) activities, were analyzed in the pellet, $40 \%$ and $80 \%$ fractions of each sperm.

\subsection{Assessment of the DGC Effectiveness in the Selection of Spermatozoa by Analyzing Oxidative Stress Profile}

The results of Fig. 1 show that MDA levels increase both in patients with normal and abnormal sperm parameters, significantly and respectively from pellet to $80 \%$ fraction, and $80 \%$ to the $40 \%$ fractions $(p=0.0004 ; p=0.03) /$ $(p=0,01 ; p=0.03)$.

In addition, lipid peroxidation level was significantly higher in patients with abnormal sperm parameters compared to patients with normal sperm parameters in pelleted fraction $(P=0.02) ; 80 \%$ fractions $(p=0.02) ; 40 \%$ fractions $(p=0.03)$.

We also noted concomitantly that the activities of the three ROS scavenging enzymes studied
(SOD, GR, CAT) increased both in patients with normal and abnormal sperm parameters from the pelletized fraction to $80 \%$ fraction, and $80 \%$ to the $40 \%$ fraction. Likewise, the activity of these enzymes was significantly higher in patients with abnormal sperm parameters compared to patients with normal parameters in pelleted fraction $(p=0.007 ; p=0.0006 ; p=0.03) ; \quad 80 \%$ fractions $(p=0.03 ; p=0.0008 ; \quad p=0.02) ; 40 \%$ fractions $(p=0.05 ; p=0.004 ; p=0.01)$ (Fig. 1).

\subsection{Evaluation of Oxidative Stress Profile after DGC in the Prediction of Pregnancy Outcomes}

In order to evaluate the impact of oxidative stress in the prediction of pregnancy, we performed a comparative analysis of the oxidative stress profile in sperm pellets commonly used in MAP of patients with positive and negative pregnancy. As shown in Table 2, we noted that MDA rate, as well as activity of antioxidant enzymes (SOD, GR, CAT), were significantly higher in patients with negative pregnancy including patients with normal and abnormal sperm parameters compared to patients with normal sperm parameters and positive pregnancy, In addition, we noted that MDA and enzymes activities levels were significantly higher in patients with abnormal sperm parameters (negative pregnancy) than those with normal sperm parameters (negative pregnancy) considered as idiopathic.

\section{DISCUSSION}

In the present study, we performed density gradient centrifugation (DGC) in patients with normal and abnormal sperm parameters and with negative or positive pregnancy. This technique is one of the methods used to improve sperm quality in MAP to select morphologically normal mobile spermatozoa. It makes it possible to obtain three sperm fractions; the pellet containing normal sperm highly mobile and viable, the $80 \%$ fraction containing abnormal spermatozoa with poor motility, and the $40 \%$ fraction containing leukocytes and cell debris [40]. We evaluated the oxidative stress in these three fractions by evaluating lipid peroxidation rate, using Malondialdyde (MDA) as a marker, one of the products formed during the decomposition of polyunsaturated fatty acids by free radicals, and the activities of the main antioxidant enzymes; superoxide dismutase (SOD) glutathione reductase (GR) and catalase (CAT). 
Debbarh et al.; ARRB, 35(12): 173-182, 2020; Article no.ARRB. 64352

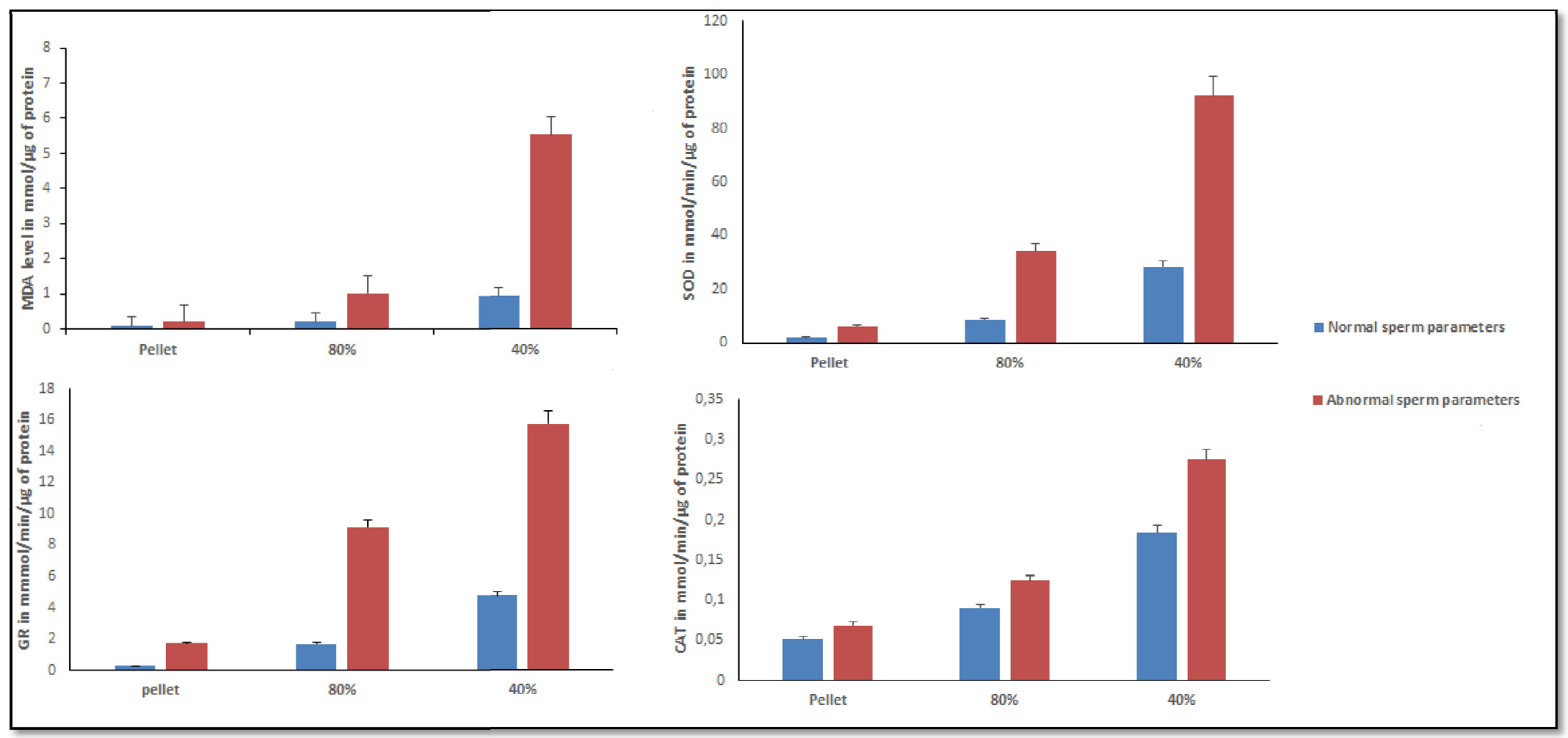

Fig. 1. Malondialdehyde (MDA) levels and antioxidant enzymes activities in mmol/pg of proteins from normal sperm parameters; and abnormal sperm parameter

Data represent mean \pm SEM. Statistical significance was defined as $p<0.05$. MDA: malondialdehyde; SOD: superoxide dismutase; GR: Glutathione reductase; CAT: catalase 
Table 2. Lipid peroxidation level (MDA) and antioxidant enzymes activities (SOD, GR, CAT) in pellets sperm of group A, group B and group C. Values are expressed in means \pm standard deviation (SD)

\begin{tabular}{|c|c|c|c|c|c|}
\hline & $\begin{array}{l}\text { Group A } \\
\text { Normal sperm } \\
\text { parameters } \\
\text { (positive pregnancy) }\end{array}$ & $\begin{array}{l}\text { Group B } \\
\text { Normal sperm } \\
\text { parameters } \\
\text { (negative pregnancy) }\end{array}$ & $\begin{array}{l}\text { Group C } \\
\text { Abnormal sperm parameters } \\
\text { (negative pregnancy) }\end{array}$ & $\begin{array}{l}F \\
\text { value }\end{array}$ & P -value \\
\hline $\begin{array}{l}\text { MDA } \\
\text { mmol } / \mu \mathrm{g} \text { of protein } \\
(\text { mean } \pm \text { SD) }\end{array}$ & $0,03 \pm 0,03$ & $0,06 \pm 0,11$ & $0,10 \pm 0,10$ & 3,92 & 0,02 \\
\hline $\begin{array}{l}\text { SOD } \mathrm{mmol} / \mathrm{min} / \mu \mathrm{g} \text { of protein } \\
(\mathrm{mean} \pm \mathrm{SD})\end{array}$ & $0,21 \pm 0,50$ & $3,29 \pm 4,15$ & $6,16 \pm 7,18$ & 5,69 & 0,005 \\
\hline $\begin{array}{l}\text { GR } \\
\mathrm{mmol} / \mathrm{min} / \mu \mathrm{g} \text { of protein } \\
(\mathrm{mean} \pm \mathrm{SD})\end{array}$ & $0,05 \pm 0,04$ & $0,45 \pm 0,48$ & $1,74 \pm 2,42$ & 9,95 & 0,0001 \\
\hline $\begin{array}{l}\text { CAT } \mathrm{mmol} / \mathrm{min} / \mu \mathrm{g} \text { of protein } \\
(\mathrm{mean} \pm \mathrm{SD})\end{array}$ & $0,02 \pm 0,04$ & $0,06 \pm 0,20$ & $0,10 \pm 0,18$ & 3,151 & 0,02 \\
\hline
\end{tabular}


The results of our study showed that the MDA level significantly decreases from the $40 \%$ fraction, $80 \%$ to the pellet fraction in both normal and abnormal sperm parameters patients. This finding demonstrates that the density gradient centrifugation method not only provides mobile and viable spermatozoa but also spermatozoa with less oxidative stress levels. These results are consistent with several studies that showed that ROS levels decrease using the density gradient centrifugation method, $[41,14,42,43,44]$. In addition, other authors explain that sperm selection by density gradient eliminates all sources of toxicity such as decapacitation factors, prostaglandin [28] and ROS [42] by eliminating white blood cells and immature spermatozoa that represent additional sources of oxidative stress. Otherwise, Enciso et al. [2011] reported that DGC was effective at removing sperm containing double-stranded DNA damage [43]. ROS have important consequences, not only in terms of peroxidation of sperm membrane and intracellular lipids and proteins but also as the major etiological factor resulting in DNA damage [44].

In addition, our study finds that idiopathic infertility patients with normal sperm parameters without pregnancy have high MDA levels compared to normal sperm parameters patients with positive pregnancy. This result is consistent with other studies [45,46,47], which concludes that the evaluation of ROS is clearly more useful in the diagnosis of infertility, as it is a much more relevant pre-indicator than conventional sperm analysis [48]. Otherwise, serval studies have deduced that more than $40 \%$ of infertile patients with no obvious cause have a high rate of free radicals $[49,50]$. Therefore, ROS measurement is particularly relevant as it may serve to identify a cause of infertility unexplained cases, which could not be identified by performing WHO semen analysis alone. Other studies have deduced that a significant number of men with normal semen parameters are infertile and have significantly higher seminal ROS levels compared to those with normal parameters who are fertile [45].

Indeed, it has been shown that high levels of ROS contribute to poor sperm parameters [51,52], impaired fertilization and sperm function $[53,54]$.

Moreover, the results obtained in this study showed that lipid peroxidation (MDA) level is significantly higher in the abnormal sperm parameters patients with negative pregnancy compared to those with normal sperm parameters group with positive or negative pregnancy. So, density gradient centrifugation associated with oxidative stress profile analysis can play a decisive role in the success of pregnancy. Furthermore, it has been shown by Yuruma et al, 2009, that high rates of noncentrifuged sperm ROS are detected in couples who have not reached pregnancy compared to couples who have already had a pregnancy [44]. In addition, our results showed enzymatic activities of superoxide dismutase (SOD), glutathione reductase (GR), and catalase (CAT) are significantly higher in normal and abnormal sperm parameters patients without pregnancy compared to normal sperm parameters patients with pregnancy. The rate of these antiradical enzymes activities decreased from the $40 \%$ fraction to the pelletized fraction. This last observation can be explained by the important presence of spermatids which shows that seminal plasma is an important source of antioxidants. Furthermore, several authors have suggested that lipid peroxidation is a consequence of an increase in the level of antiradical enzymes, $[55,56,57,58,59]$. On the other hand, the antioxidants would prevent or potentially repair oxidative damage. Unregulated supplementation of antioxidants can induce a pathological imbalance between oxidation and reduction. The antioxidant paradox describes how antioxidants can exacerbate damage through a loss of oxidative mechanisms, promotion of tissue lesion, and a paradoxical increase in ROS [60]. As discussed before, oxidation plays a material role in male reproduction and unregulated antioxidant supplementation can affect these mechanisms. Surplus CAT can inhibit capacitation by impeding local oxidation [61]. Similarly, excess SOD and CAT can prevent acrosome reaction occurrence [62].

\section{CONCLUSION}

All of these results show that, on the one hand, DGC makes it possible to obtain a pellet containing spermatozoa that is both mobile and viable and that has less oxidative stress. On the other hand, the rate of lipid peroxidation allows not only to differentiate between normal and abnormal sperm parameters in infertile patients but also it enables to differentiate between infertile patients with and without pregnancy. 


\section{CONSENT}

All authors declare that 'written informed consent was obtained from all patients for publication of this Research.

\section{COMPETING INTERESTS}

Authors have declared that no competing interests exist

\section{REFERENCES}

1. Rowe $\mathrm{P}$, Comhaire $\mathrm{F}$, Hargreave $\mathrm{T}$, Mahmoud A. WHO Manual for the standardized Investigation, Diagnosis and Management of the Infertile Male. Cambridge Univ Press; 2000.

2. Berkowitz JM. Mummy was a fetus: Motherhood and fetal ovarian transplantation. J Med Ethics. 1995;21:298-304.

3. Thonneau $P$, Marchand $S$, Tallec A, Ferial $\mathrm{ML}$, Ducot B, Lansac J, et al. Incidence and main causes of infertility in a resident population (1850000) of three french regions (1988-1989). Hum Reprod. 1991;6:811-6.

4. Chapuis A, Gala A, Ferrières-Hoa A, Mullet $T$, Bringer-Deutsch $S$, Vintejoux $E$, et al. Sperm quality and paternal age: Effect on blastocyst formation and pregnancy rates. Basic Clin Androl. 2017;27.

5. Bungum M. Sperm DNA Integrity Assessment: A New Tool in Diagnosis and Treatment of Fertility. Obstet Gynecol Int. 2012:1-6.

6. Sergerie M, Laforest G, Bujan L, Bissonnette F, Bleau G. Sperm DNA fragmentation: Threshold value in male fertility. Hum Reprod. 2005;20:3446-51.

7. Gibbons WE. Unexplained infertility Unexplained infertility. Fertil Steril. 2014;39:19-23.

8. John Aitken R, De luliis GN, Drevet JR. Role of oxidative stress in the etiology of male infertility and the potential therapeutic value of antioxidants. Oxid. Antioxidants, Impact Oxidative Status Male Reprod. Elsevier. 2018;91-100.

9. Xing J. AB042.Oxidative stress and male infertility. Transl Androl Urol. 2018;7:AB042-AB042.

10. Saalu LC. The incriminating role of reactive oxygen species in idiopathic male infertility: An evidence based evaluation. Pakistan J Biol Sci. 2010;13:413-22.
11. Tvrdá E, Kňažická Z, Bárdos L, Massányi $P$, Lukáč $N$. Impact of oxidative stress on male fertility - A review. Acta Vet Hung 2011;59:465-84.

12. Aitken R. Molecular mechanisms regulating human sperm function. Mol Hum Reprod. 1997;3:169-73.

13. Aitken RJ. The Amoroso Lecture The human spermatozoon - a cell in crisis? Reproduction. 1999;115:1-7.

14. Henkel RR, Schill WB. Sperm preparation for ART. Reprod Biol Endocrinol. 2003;1.

15. Sánchez R, Sepúlveda C, Risopatrón J, Villegas J, Giojalas LC. Human sperm chemotaxis depends on critical levels of reactive oxygen species. Fertil Steril. 2010;93:150-3.

16. Agarwal A, Nallella KP, Allamaneni SS, Said TM. Role of antioxidants in treatment of male infertility: An overview of the literature. Reprod Biomed Online. 2004;8:616-27.

17. Griveau JF, Le Lannou D. Reactive oxygen species and human spermatozoa: Physiology and pathology. Int J Androl. 1997;20:61-9.

18. Fraga CG, Motchnik PA, Shigenaga MK, Helbock HJ, Jacob RA, Ames BN. Ascorbic acid protects against endogenous oxidative DNA damage in human sperm. Proc Natl Acad SciUSA. 1991;88:11003-6.

19. Zini A, Finelli A, Phang D, Jarvi K. Influence of semen processing technique on human sperm DNA integrity. Urology. 2000;56:1081-4.

20. Barroso G, Morshedi M, Oehninger S. Analysis of DNA fragmentation, plasma membrane translocation of phosphatidylserine and oxidative stress in human spermatozoa. Hum Reprod. 2000;15:1338-44.

21. De Lamirande E, Gagnon C. Impact of reactive oxygen species on spermatozoa: A balancing act between beneficial and detrimental effects. Hum. Reprod. 1995;10:15-21.

22. Iwasaki A, Gagnon C. Formation of reactive oxygen species in spermatozoa of infertile patients. Fertil Steril. 1992;57:409_ 16.

23. Lopes S, Jurisicova A, Sun JG, Casper RF. Reactive oxygen species: Potential cause for DNA fragmentation in human spermatozoa. Hum Reprod. 1998;13:896900.

24. Pasqualotto FF, Sundaram A, Sharma RK, Borges Jr E, Pasqualotto EB, Agarwal A. 
Semen quality and oxidative stress scores in fertile and infertile patients with varicocele. Fertility and Sterility. 2008; 89(3):602-607.

25. Dorostghoal $M$, Kazeminejad SR, Shahbazian N, Pourmehdi M, Jabbari A. Oxidative stress status and sperm DNA fragmentation in fertile and infertile men. Andrologia. 2017;49(10):12762.

26. Krausz C, Mills C, Rogers S, Tan SL, Aitken RJ. Stimulation of oxidant generation by human sperm suspensions using phorbol esters and formyl peptides: Relationships with motility and fertilization in vitro. Fertil Steril. 1994;62:599-605.

27. Sukcharoen N, Keith J, Irvine DS, Aitken RJ. Predicting the fertilizing potential of human sperm suspensions in vitro: Importance of sperm morphology and leukocyte contamination. Fertil Steril. 1995;63:1293-300.

28. Sukcharoen N, Keith J, Irvine DS, Aitken RJ. Prediction of the in-vitro fertilization (IVF) potential of human spermatozoa using sperm function tests: The effect of the delay between testing and IVF. Hum Reprod. 1996;11:1030-4.

29. Centola GM, Herko R, Andolina E, Weisensel S. Comparison of sperm separation methods: Effect on recovery, motility motion parameters and hyperactivation. Fertil Steril. 1998;70:1173-5.

30. Mathieu C, Lucas $\mathrm{H}$. Tests de selection des spermatozoides avant assistance medicale a la procreation. Andrologie. 1999;9:286-94.

31. FORD WCL. The role of oxygen free radicals in the pathology of human spermatozoa: Implications of IVF. Clin IVF Forum Curr Views Assist Reprod Manchester Univ. 1990:123-39.

32. Mortimer D. Sperm preparation techniques and iatrogenic failures of in-vitro fertilization. Hum Reprod. 1991;6:173-6.

33. Kruger TF, Menkveld R, Stander FSH, Lombard CJ, Van der Merwe JP, van Zyl JA, et al. Sperm morphologic features as a prognostic factor in in vitro fertilization. Fertil Steril. 1986;46:1118-23.

34. Aboulmaouahib S, Madkour A, Kaarouch I, Saadani B, Sefrioui O, Louanjli N, et al. Effect of semen preparation technique and its incubation on sperm quality in the Moroccan population. Andrologia. 2017;49.

35. Bradford MM. A rapid and sensitive method for the quantitation of microgram quantities of protein utilizing the principle of protein-dye binding. Anal Biochem. 1976;72:248-54.

36. Samokyszyn VM, Marnett LJ. Inhibition of microsomal lipid peroxidation by 13-cisretinoic acid. Methods Enzymol. 1990; 190:281-8.

37. Paoletti F, Aldinucci D, Mocali A, Caparrini A. A sensitive spectrophotometric method for the determination of superoxide dismutase activity in tissue extracts. Anal Biochem. 1986;154:536-41.

38. Di llio C, Polidoro G, Arduini A, Muccini A, Federici G. Glutathione peroxidase, glutathione reductase, glutathione $S$ transferase, and $\mathrm{y}$-glutamyltranspeptidase activities in the human early pregnancy placenta. Biochem Med. 1983;29:143-8.

39. Aebi $H$. Catalase in Vitro. Methods Enzymol. 1984;105:121-6.

40. Allamaneni SSR, Agrawal A, Rama S, Ranganathan P, Sharma RK. Comparative study on density gradients and swim-up preparation techniques utilizing neat and cryopreserved spermatozoa. Asian J Androl. 2005;7:86-92.

41. Takeshima $\mathrm{T}$, Yumura $\mathrm{Y}$, Kuroda $\mathrm{S}$, Kawahara T, Uemura H, Iwasaki A. Effect of density gradient centrifugation on reactive oxygen species in human semen. Syst Biol Reprod Med. 2017;63:192-8.

42. AITKEN RJ, CLARKSON JS. Significance of Reactive Oxygen Species and Antioxidants in Defining the Efficacy of Sperm Preparation Techniques. J Androl. 1988;9:367-76.

43. Enciso M, Iglesias M, Galán I, Sarasa J, Gosálvez A, Gosálvez J. The ability of sperm selection techniques to remove single-or double-strand DNA damage. Asian J Androl. 2011;13:764-8.

44. Yumura $Y$, Iwasaki A, Saito K, Ogawa T, Hirokawa M. Effect of reactive oxygen species in semen on the pregnancy of infertile couples: Original Article: Clinical Investigation. Int J Urol. 2009;16:202-7.

45. Aitken RJ, Smith TB, Jobling MS, Baker MA, De luliis GN. Oxidative stress and male reproductive health. Asian J Androl. 2014;16:31-8.

46. Pasqualotto FF, Sharma RK, Kobayashi $H$, Nelson DR, Thomas AJ, Agarwal A. Oxidative stress in normospermic men undergoing infertility evaluation. J Androl. 2001;22:316-22.

47. Pasqualotto FF, Sharma RK, Pasqualotto EB, Agarwal A. Poor semen quality and 
ROS-TAC scores in patients with idiopathic infertility. Urol Int. 2008;81:263-70.

48. Haiba F, Kerboua K, Ait Hami N, et al. Stress oxydatif et infertilité masculine: premiers résultats de l'expérience algérienne pilote à l'HMRUO/2 RM. Rev Médicale l'HMRUO. 2014:1-2014.

49. Deepinder F, Cocuzza M, Agarwal A. Should seminal oxidative stress measurement be offered routinely to men presenting for infertility evaluation? Endocr Pract. 2008;14:484-91.

50. Wagner $\mathrm{H}$, Cheng JW, Ko EY. Role of reactive oxygen species in male infertility: An updated review of literature. Arab J Urol. 2018;16:35-43.

51. Dandekar SP, Nadkarni GD, Kulkarni VS, Punekar S. Lipid peroxidation and antioxidant enzymes in male infertility. J Postgrad Med. 2002;48:186-9.

52. Agarwal A, Makker K, Sharma R. Clinical relevance of oxidative stress in male factor infertility: An update. Am J Reprod Immunol. 2008;59:2-11.

53. Tremellen K, King B V, Li HCX, Lu YCW. Oxidative Stress and Male Infertility: A Clinical Perspective Oxidative stress and male infertility - a clinical perspective Antioxidant Therapy for the Enhancement of Male Reproductive Health: A Critical Review of the in human seminal plasma: Determin. Hum Reprod Update. 2018; 25:2018.

54. Aitken RJ, Finnie JM, Muscio L, Whiting S, Connaughton HS, Kuczera L, et al. Potential importance of transition metals in the induction of DNA damage by sperm preparation media. Hum Reprod. 2014; 29:2136-47.
55. Potts RJ, Mjefferies T, Notarianni LJ. Antioxidant capacity of the epididymis. Hum Reprod. 1999;14:2513-6.

56. Alkan I, Şimşek F, Haklar G, Kervancioğlu $E$, Özveri $H$, Yalçin $S$, et al. Reactive oxygen species production by the spermatozoa of patients with idiopathic infertility: Relationship to seminal plasma antioxidants. J Urol. 1997;157:140-3.

57. Siciliano L, Tarantino $\mathrm{P}$, Longobardi $\mathrm{F}$, Rago V, De Stefano C, Carpino A. Impaired seminal antioxidant capacity in human semen with hyperviscosity or oligoasthenozoospermia. J Androl. 2001;22:798-803.

58. Storey B. Biochemistry of the induction and prevention of lipoperoxidative damage in human spermatozoa. Mol Hum Reprod. 1997;3:203-13.

59. Murawski M, Saczko J, Marcinkowska A, Chwiłkowska A, Gryboś $M$, Banaś $T$. Evaluation of superoxide dismutase activity and its impact on semen quality parameters of infertile men. Folia Histochem. Cytobiol. 2007;45:123-6.

60. Halliwell B. The antioxidant paradox. Lancet. 2000;355:1179-80.

61. Aitken RJ, Paterson $M$, Fisher $H$, Buckingham DW, van Duin M. Redox regulation of tyrosine phosphorylation in human spermatozoa and its role in the control of human sperm function. J Cell Sci. 1995;108:2017-25.

62. De Lamirande E, Tsai C, Harakat A, Gagnon C. Involvement of reactive oxygen species in human sperm arcosome reaction induced by A23187, lysophosphatidylcholine, and biological fluid ultrafiltrates. J Androl. 1998;19:58594.

(c) 2020 Debbarh et al.; This is an Open Access article distributed under the terms of the Creative Commons Attribution License (http://creativecommons.org/licenses/by/4.0), which permits unrestricted use, distribution, and reproduction in any medium, provided the original work is properly cited.

Peer-review history:

The peer review history for this paper can be accessed here: http://www.sdiarticle4.com/review-history/64352 